${ }^{1}$ Department of Internal Diseases, Diabetology and Cardiometabolic Diseases, Faculty of Medical Sciences in Zabrze, Medical University of Silesia in Katowice, Poland

${ }^{2}$ Department of Cardiac, Vascular and Endovascular Surgery and Transplantology, Faculty of Medical Sciences in Zabrze, Medical University of Silesia in Katowice, Poland

${ }^{3}$ Department of Cardiac Transplantation and Mechanical Circulatory Support, Silesian Center for Heart Diseases, Zabrze, Poland; First Chair

of General Surgery, Jagiellonian University Medical College, Kraków, Poland

\title{
New Onset Diabetes After Transplantation (NODAT) - scientific data review
}

\section{ABSTRACT}

New onset diabetes after transplantation (NODAT) is one of the most common and serious complications of solid organ transplantation. The incidence of NODAT is estimated to range from $2 \%$ to $53 \%$.

Patients who develop new onset diabetes after transplantation are significantly more frequently exposed to a higher risk of death and cardiovascular incidents as well as other adverse effects, such as decreased patient survival, higher infection rates and early graft loss. Identifying high-risk patients, undertaking preventive action and applying appropriate treatment can limit the development of new onset diabetes after transplantation and improve a patient's long-term prognosis. (Clin Diabetol 2020; 9; 5: 356-366)

Key words: new onset diabetes after transplantation, risk factors, diagnostics, treatment

\section{Introduction}

The second half of the $20^{\text {th }}$ century was a time of the extremely rapid development and advancement of transplant medicine. Perfecting the immunosuppressive protocol resulted in organ transplantation becoming

Address for correspondence:

Katarzyna Zielińska, MD

Department of Internal Diseases

Diabetology and Cardiometabolic Diseases

Faculty of Medical Sciences in Zabrze

Medical University of Silesia in Katowice

M. Curie-Skłodowskiej 9, 41-800 Zabrze, Poland

Phone: +48663713131

e-mail: katarzynaxzielinska@gmail.com

Clinical Diabetology 2020, 9; 5: 356-366

DOI: $10.5603 /$ DK.2020.0047

Received: 26.06 .2020

Accepted: 01.11.2020 more common and consequently led to increasingly better postoperative care, which is conducive to extended patient survival and significantly improves a patient's quality of life.

A major success was achieved in terms of early perioperative complications - there is a considerable decline in the frequency of infectious and immunological complications that influence acute rejection [1]. Presently, when striving to achieve further development with the aim of improving patient survival and quality of life, it is necessary to understand the long-term complications such as allograft vasculopathy or new onset diabetes after transplantation (and reduce them to the minimum) [2].

Hyperglycemia, which develops as a result of stress related to the transplantation surgery or the administration of high doses of steroids, persists in most patients exclusively during a short period of hospitalization following an operation. However, the administration of immunosuppressants, combined with predisposing risk factors, increases the incidence of NODAT [3].

\section{Definition}

There are several terms found in literature that describe diabetes developed after organ transplantation. One of them is "new onset diabetes after transplantation" (NODAT), though it exclusively encompasses those patients, who were diagnosed as diabetic only after organ transplantation and it excludes patients with diabetes diagnosed prior to the transplant, as well as those with hyperglycemia that remits over the course of a short period after the surgery. Cases of undiagnosed diabetes are related to the lack of standardized examination protocols before transplantation, as OGTT provides positive results in over $70 \%$ of patients despite 
normal fasting plasma glucose levels being found before transplantation [4].

The term "post-transplant diabetes mellitus" (PTDM) has undergone changes, as initially it only encompassed the onset of diabetes after solid organ transplantation following a period of 30 days, which required insulin treatment. However, the term was reintroduced in 2014 and now encompasses patients with persisting hyperglycemia (most likely as a result of existing diabetes that failed to be diagnosed prior to a transplant), NODAT patients and individuals with temporary post-transplant hyperglycemia that remits within 1 year following transplantation. One of the reasons for applying PTDM terminology is that screening tests for undiagnosed diabetes during transplantation are often performed ineffectively [5].

These terms do not have synonymous definitions, so they should not be used interchangeably, although they are frequently applied in such a manner.

Temporary hyperglycemia is not classified as diabetes, as the diagnosis can be made without ongoing acute rejection processes and infection, as well as after the immunosuppressant doses are lowered [6].

An additional term was introduced by Bloom et al. [7], "transplant-associated hyperglycemia" (TAH), which encompasses both diabetes and prediabetic states after organ transplantation.

\section{Diagnosis}

The diagnosis of NODAT-type diabetes is performed using unmodified criteria for diagnosing diabetes in the general population, based on acknowledged World Health Organization (WHO) criteria proposed by the American Diabetes Association (ADA) [8, 9].

The standard definition is as follows:

- random plasma glucose concentration $\geq 200 \mathrm{mg} / \mathrm{dL}$ with concomitant symptoms such as polyuria, polydipsia and unexplained weight loss;

- fasting plasma glucose concentration $\geq 126 \mathrm{mg} / \mathrm{dL}$, where "fasting" entails at least 8 hours without calorie intake;

- plasma glucose concentration $\geq 200 \mathrm{mg} / \mathrm{dL}$ two hours after the oral ingestion of $75 \mathrm{~g}$ of anhydrous glucose dissolved in water.

The gold standard for NODAT diagnosis is the oral glucose tolerance test. The fasting plasma glucose and $\mathrm{HbA}_{1 \mathrm{c}}$ tests performed during screening examinations can identify high-risk patients who require further diagnostics [10].

\section{Incidence}

The incidence of new onset diabetes after transplantation varies, depending on the transplanted organ, the duration of the observation period, the applied immunosuppressive therapy and the presence of risk factors. NODAT occurs in $4 \%$ to $25 \%$ of kidney transplant patients; $4 \%$ to $40 \%$ of heart transplant recipients; $30 \%$ to $35 \%$ of lung transplant patients; and $2.5 \%$ to $25 \%$ of liver transplant recipients [11]. The differences in the described incidence rates are a result of the lack of a uniform definition of diabetes diagnosis through testing as well as the lack of diagnostic methods, different patient observation periods and the presence of both modifiable and non-modifiable factors.

Therefore the discrepancy between the published results of various studies is considerable - the occurrence of NODAT is found in $2 \%$ to $53 \%$ of solid organ transplant recipients [12]. The incidence increases together with the time that passes after organ transplantation, though the disease develops most frequently within the first year following surgery.

\section{NODAT pathophysiology}

The pathophysiology of the development of new onset diabetes after transplantation is not fully understood, though it is recognized that it encompasses dysfunctions of pancreatic beta cells, increased glycogenesis in the liver and coexisting increased insulin resistance. The distinguishing aspect of new onset diabetes after transplantation is the original pathophysiological defect that is the dysfunction of pancreatic beta cells, whereas type 2 diabetes begins with insulin resistance [13]. Genetic predispositions and individual factors also have significant influence on the development of NODAT.

\section{Clinical forms}

Hjelmesaeth et al. [14] proposed a division of new onset diabetes after transplantation into three clinical forms (Table 1).

\section{NODAT risk factors}

The risk factors presented in the table below were divided based on the possibility of modification (Table 2). The factors that are not subject to modification facilitate the identification of high-risk patients, whereas the remaining factors serve to reduce the risk of developing NODAT and to prevent long-term complications [15].

\section{Non-modifiable risk factors}

\section{Age}

Age is the most significant risk factor for developing new onset diabetes after transplantation. In their study, Cosio et al. [16] demonstrated that among 2078 kidney transplant recipients, the likelihood of developing diabetes in patients aged over 45 was 2.9 times 
Table 1. Division of new onset diabetes after transplantation into 3 clinical forms

\begin{tabular}{|c|c|c|c|}
\hline & I & II & III \\
\hline Time of occurrence & $\begin{array}{c}\text { Very early period after } \\
\text { transplantation (3-6 months) }\end{array}$ & Post-transplant period & $\begin{array}{c}\text { Late period } \\
\text { (after } 6 \text { months) }\end{array}$ \\
\hline \multirow[t]{2}{*}{ Pathophysiology } & $\begin{array}{l}\text { Insulin resistance due } \\
\text { to high doses of GCS }\end{array}$ & $\begin{array}{l}\text { Insulin synthesis } \\
\text { and secretion disorders }\end{array}$ & Intensified insulin resistance \\
\hline & & Glucose metabolism disorders & Impaired insulin secretion \\
\hline Treatment & Diabetic diet & Insulin therapy required & $\begin{array}{c}\text { Hypoglycemic treatment } \\
\text { usually required }\end{array}$ \\
\hline Lowered prednisone doses & Improved glucose metabolism & $\begin{array}{l}\text { No plasma glucose } \\
\text { improvements }\end{array}$ & $\begin{array}{l}\text { Low doses administered during } \\
\text { immunosuppressive therapy }\end{array}$ \\
\hline
\end{tabular}

Table 2. Risk factors for developing new onset diabetes after transplantation

\begin{tabular}{lcc}
\hline Non-modifiable & Partially modifiable & Modifiable \\
\hline Age $>45$ years & Hepatitis C & Immunosuppressive therapy \\
Ethnic group (African American, Hispanic) & CMV infection & Rejection episodes \\
The male sex & Prediabetic state & Weight gain or obesity \\
Family history of diabetes & Biochemical disorders (including & Metabolic syndrome \\
& hypermagnesemia, hyperuricemia) & \\
Large number of incompatible antigens & Hypertriglyceridemia before & Antihypertensive medication \\
in the HLA system & transplantation & (e.g. thiazide diuretics, beta-blockers) \\
Genetic polymorphisms & & \\
Donor's characteristics & & \\
Polycystic kidney disease & & \\
\hline
\end{tabular}

greater compared to younger patients at the time of the transplantation $(\mathrm{RR}=2.2, \mathrm{P}<0.0001)$. Some authors place the threshold slightly higher, e.g. Ye et al. [17] concluded that the risk increases for an age of over 50 years $(H R=1.20$ for an age $\geq 50$ years vs. $<50$, $P=0.01)$. On the other hand, statistics of the United States Renal Data System (USRDS) indicate that an age of over 60 years significantly increases the risk of NODAT (RR $=2.6, \mathrm{P}<0.0001$ ), and furthermore, the risk of developing diabetes increases by 1.5 times for every 10 years of age [18].

\section{Ethnic group}

The occurrence of new onset diabetes after transplantation is observed much more frequently in Americans of African descent and patients of Hispanic descent (respectively: African Americans $[R R=1.68$, $\mathrm{P}<0.0001]$ and Hispanics $[R R=1.35, \mathrm{P}<0.0001])$ compared to the white population [18]. This difference may be related to the genetic diversity of the patients, and the inconsistency in pharmacokinetics and immunosuppressant effects. It was also indicated that there is a strong diabetogenic effect in African Americans after the administration of tacrolimus, which influences the predispositions for the occurrence of NODAT.

\section{The male sex}

The publication by Dedinská et al. [19] confirmed the influence of the male sex as a risk factor, as well as the existence of significant differences with regard to the development of new onset diabetes after transplantation. Female patients exhibit pancreatic beta cell dysfunctions, whereas insulin resistance and the metabolic syndrome are dominant in men.

\section{Family history of diabetes}

Both genetic and environmental factors influence the development of NODAT. Studies confirmed that the risk of developing new onset diabetes after transplantation increases sevenfold in first-degree relatives [20]. In the publication by Martinez-Castelao et al. [21] regarding solid organ recipients, a positive family history was associated with a $50 \%$ increase in NODAT risk. 
Table 3. Potential diabetogenic effects of immunosuppressants

\begin{tabular}{ll}
\hline Immunosuppressants & Potential diabetogenic effects \\
\hline Ciclosporin & $\cdot \downarrow$ insulin secretion \\
& $\cdot \downarrow$ insulin synthesis \\
& $\cdot \downarrow \beta$ cell density \\
\hline Tacrolimus & $\cdot \downarrow$ insulin secretion \\
& $\cdot \downarrow$ insulin synthesis \\
\hline Sirolimus & $\cdot \uparrow$ peripheral insulin resistance \\
\hline Everolimus & impaired pancreatic $\beta$ cell response \\
\hline Glucocorticosteroids & $\bullet \downarrow$ glycolysis and pentose phosphate pathway activity \\
& $\cdot \uparrow$ gluconeogenesis in the liver \\
& $\cdot$ Conducive to protein degradation for amino acid release in muscles, lipolysis
\end{tabular}

\section{Number of incompatible antigens in the HLA system}

The development of NODAT is associated with the presence of certain human leukocyte antigens (HLA): A30, B27 and B42 [15].

\section{Partially modifiable risk factors \\ Hepatitis C}

Hepatitis $C$ infection is a predisposing factor for the more frequent occurrence of new onset diabetes after transplantation in the population of post-solid organ transplant patients. Studies indicate that treatment using interferon alfa significantly improves plasma glucose levels in this group of patients. The pathophysiology of HCV is still unclear. It is assumed that the diabetogenic mechanism of the HCV infection encompasses the direct cytopathic effect of the virus on pancreatic beta cells, insulin resistance, and inhibited glycogenesis and glucose uptake in the liver [7]. Baid et al. [22] concluded that an HCV infection had an independent correlation with a $62 \%$ increase in insulin resistance $(P=0.0005)$.

\section{CMV infection}

Asymptomatic cytomegalovirus infections and the CMV disease are independent risk factors for new onset diabetes after transplantation. The studies by Hjelmesaeth et al. [23] found that patients with active cytomegalovirus infections exhibited a considerably lower median of insulin release compared to the control group, and their risk of developing NODAT was four times as great $(R R=4.00, P=0.025)$. This dependence, described during CMV infections, was most likely the result of the influence of inflammatory cytokines, which damage the pancreatic beta cells and result in their apoptosis [24]. The described dependence was confirmed in numerous publications, yet it was not proven in all of them [1].

\section{Modifiable risk factors}

\section{Immunosuppressive therapy (Table 3)}

- Calcineurin inhibitors: ciclosporin and tacrolimus;

- mTOR inhibitors: sirolimus and everolimus;

- glucocorticosteroids.

\section{Rejection episodes}

Acute rejection is associated with a risk of developing new onset diabetes after transplantation, though the cause of its occurrence is idiopathic. Most frequently, the rejection is followed by high-dose pulse glucocorticosteroid (GCS) therapy, which constitutes the basis for the treatment of cases of acute rejection and which is considered to be the underlying cause of hyperglycemia [25].

\section{Weight gain or obesity}

Weight gain is a significant factor influencing the development of new onset diabetes after transplantation [26], though not all publications confirm this dependence [27]. It is only such weight gain that results in overweight or obesity that is classified as a risk factor. Some of the patients were malnourished during conservative treatment prior to transplantation. It was only the increase in hunger combined with insulin resistance and the administration of high doses of steroids at low physical activity that resulted in rapid weight gain. This emphasizes the necessity to introduce modifications to a patient's lifestyle and nutritional habits before transplantation. 


\section{Diagnostic tools}

Despite the existence of numerous studies that asses the risk of the occurrence of new onset diabetes after transplantation, there is still no detailed model of diagnostic methods that could be applied to post-solid organ transplant patients, which would enable the early identification of high-risk NODAT patients. As a result of the applied immunosuppressive therapy, plasma glucose levels undergo rapid changes in the early postoperative period. Fasting plasma glucose tests, oral glucose tolerance tests and $\mathrm{HbA}_{1 \mathrm{c}}$ tests all evaluate a different scope of glucose metabolism.

The oral glucose tolerance test (OGTT) is considered the gold standard in NODAT diagnostics.

Fasting plasma glucose tests (FPG) performed during immunosuppressive therapy do not provide an adequate representation of the body's carbohydrate metabolism. However, FPG is preferred during outpatient care since it is quick and easy to perform, as well as due to the low cost of testing and high patient comfort.

Glucocorticosteroids achieve their maximum effect within 8 hours after administration, which consequently means that this effect is typically attained during afternoon hours. In the first weeks after transplantation, it seems valid to perform additional plasma glucose tests in the afternoon [28].

Recent studies emphasize the importance of measuring the level of plasma glucose during afternoon hours and using the level of glycated hemoglobin $\left(\mathrm{HbA}_{1 \mathrm{c}}\right)$.

Although the results of the test provide correlations with the occurrence of complications of diabetes in the early period, considering the presence of confounding factors, its performance is inadvisable [29].

\section{Clinical recommendations}

Given the diagnostic difficulties, it would appear valid to identify patients belonging to the potential risk group for the development of new onset diabetes after transplantation, but this is problematic due to the numerous modifiable and non-modifiable factors that influence its occurrence.

However, already at the stage of NODAT diagnosis, the most important measure is to modify a patient's lifestyle in a manner that would include changes to dietary habits aimed primarily at weight loss, giving up smoking and regular exercise.

\section{Immunosuppressive therapy}

Immunosuppressant doses need to be modified in order to minimize the likelihood of developing new onset diabetes after transplantation. In the case of glucocorticosteroids, it is recommended to limit the doses to the minimum or to terminate the administration of steroids altogether. Yet some researchers claim that terminating the administration of steroids during therapy does not provide additional benefits and it may furthermore intensify the risk of the occurrence of acute rejection. For this reason, it is important to conduct regular therapy monitoring in order to introduce hypoglycemic treatment immediately after the onset of the first symptoms of diabetes [14]. However, in the case of kidney transplant patients, steroid therapy must be conducted longer and with higher doses compared to other organ transplant recipients due to the high risk of rejection. In the case of tacrolimus, it is recommended to lower the doses or convert to sirolimus or ciclosporin [30].

\section{Ciclosporin (CsA)}

Calcineurin inhibitors $(\mathrm{CNI})-$ ciclosporin and tacrolimus - affect calcineurin, the T-lymphocyteactivating protein, by inhibiting the activation of T-lymphocytes and the expression of cytokine genes. Ciclosporin damages the cells of insulin-producing pancreatic islets and inhibits the synthesis and glucose-dependent secretion of insulin. Ciclosporin extends the duration of action of steroids in the patient's organism and influences the development of NODAT, but to an extent lesser compared to tacrolimus.

\section{Tacrolimus (Tac)}

Among the immunosuppressants used in solid organ transplantation protocols, tacrolimus is characterized by the strongest diabetogenic effects [15].

The multi-center DIRECT trial, assessing glucose abnormalities after kidney transplantation, described a significantly higher incidence of abnormal fasting plasma glucose levels six months after transplantation as well as of NODAT in patients treated using tacrolimus ( $34 \%$ vs. $26 \%, P=0.046$ ). The group of patients treated with tacrolimus required hypoglycemic treatment and significantly more frequently required therapy combined with insulin [31].

In the studies published in 2004, Heisel et al. [32] discovered a higher incidence of insulin-dependent diabetes mellitus (IDDM) in liver, heart and lung transplant recipients treated with Tac. $9.8 \%$ of kidney transplant recipients treated with Tac developed IDDM, compared to $2.7 \%$ of patients treated with CsA $(P<0.00001)$. Similar tendencies were observed in recipients of solid organs other than kidneys - $11.1 \%$ compared to $6.2 \%$ respectively $(P<0.003)$. Not all the studies demonstrated Tac to be more diabetogenic than ciclosporin. It is suggested that these discrepancies in the studies were partially influenced by the differences in the 
Table 4. Summary of diabetogenic effects of immunosuppressants

\begin{tabular}{lcccccc}
\hline Drug & CsA & Tac & Sirolimus & Everolimus & MMF & AZA \\
\hline Glucose metabolism disorders: & ++ & +++ & + & + & - & \\
\hline
\end{tabular}

definition of NODAT, and the differences in the doses of calcineurin inhibitors and the concentration of the medication [33]

\section{Sirolimus}

Sirolimus exhibits diabetogenic effects, whereas combination therapy with tacrolimus and sirolimus is related to a greater incidence of NODAT than in the case of immunosuppressive therapy using only tacrolimus [34]. The multi-center studies published in 2008, based on the analysis of the USRDS (United States Renal Data System) database consisting of 20,124 primary kidney transplant recipients receiving sirolimus, calcineurin inhibitors or both in various combination therapies with an antimetabolite - mycophenolate mofetil (MMF) or azathioprine (AZA) — Johnston et al. [35] demonstrated that patients treated with sirolimus in combination with CNI (CsA or Tac) exhibited the greatest incidence of NODAT. Furthermore, the authors found that the risk of developing NODAT in patients treated by means of combination therapy (Sir + Tac) was 1.9 compared to patients receiving (Tac + MMF/AZA), which suggests that sirolimus was associated with a greater risk of NODAT incidence regardless of the influence of tacrolimus.

\section{Everolimus}

Everolimus is another available mTOR inhibitor. Although there are fewer studies assessing its mode of action and its influence on glucose metabolism, there is no data suggesting that its influence on the risk of developing post-transplant diabetes mellitus is different compared to sirolimus.

\section{Mycophenolate mofetil (MMF) \\ and azathioprine (AZA)}

The antimetabolites AZA and MMF were not found to be diabetogenic; on the contrary - it is suggested that the simultaneous administration of MMF alleviates the diabetogenic effects of tacrolimus. The use of azathioprine or MMF enables the administration of lower doses of other diabetogenic immunosuppressants.

\section{Summary (Table 4)}

The immunosuppressive therapy must be modified in the event of the occurrence of post-transplant diabe- tes mellitus. According to the KIDIGO recommendations it is advised to:

- reduce the doses or terminate the administration of Tac, CsA and steroids;

- replace Tac with CsA, MMF or AZA;

- replace CsA with MMF or AZA.

Combining CNI with mTOR inhibitors (mTORi) and substituting mTORi for Tac is not recommended due to the increase in insulin resistance [36].

\section{Hypoglycemic treatment}

The basis for treating post-transplant patients is the individualization of the treatment regimen and its adaptation to a given patient and plasma glucose level. There is no common therapy model for NODAT, but recommendations for the general population are applied, modified on the basis of immunosuppressive therapy.

Metformin increases insulin sensitivity and is recommended for patients with good renal function (eGFR $>60 \mathrm{~mL} / \mathrm{min}$ ). The glomerular filtration rate often exhibits appropriate increase in the case of properly functioning grafts, thanks to which the drug can be safely administered to most patients and it constitutes the first oral medication used in the treatment of NODAT. If combination therapy is required, metformin can be coadministered with new anti-diabetic medication or insulin [37].

The main disadvantage of administering metformin is the exposure of the patient to gastrointestinal disorders as a result of the effects of immunosuppressants such as mycophenolate mofetil [38].

However, given the beneficial influence on body mass reduction, metformin is used as a first-line drug following body mass increase related to the administration of glucocorticosteroids.

Contraindications for the administration of metformin include:

- hypersensitivity to the active substance or to any excipient;

- diabetic ketoacidosis, diabetic pre-comatose state;

- renal function failure or disorders (creatinine clearance $<60 \mathrm{~mL} / \mathrm{min}$ );

- acute states with risk of renal function disorders, such as: dehydration, severe infection, shock, intravascular administration of iodinated contrast agents; 
- acute or chronic diseases that may result in tissue hypoxia, such as: heart failure or respiratory failure, recent myocardial infarction, shock;

- liver failure, acute alcohol poisoning, alcoholism;

- breastfeeding.

The new generation of thiazolidinediones can be used without drug interaction with immunosuppressive therapy administered after transplantation. The use of thiazolidinediones in the treatment of PTDM was studied in cases of kidney and liver transplants, but not heart transplant. Several studies revealed that this group of drugs is effective in decreasing $\mathrm{HbA}_{1 \mathrm{c}}$ both in monotherapy and in coadministration with other antidiabetic medications, with no significant interactions with ciclosporin and/or tacrolimus. Unfortunately, these studies were characterized by considerable limitations - first of all, there was no control group and the immunosuppressive treatment regimens were diverse, which made it difficult to provide a precise assessment of the treatment efficiency. Additionally, these studies were conducted using outdated diagnostic criteria for NODAT. Thiazolidinediones are strongly associated with a number of adverse effects - body mass increase (by $2 \%$ in the case of monotherapy and by $5 \%$ when coadministered with sulfonylureas or insulin [39], fluid retention and heart failure, increased risk of fractures in women [40] and possibly increased risk of bladder cancer [41]. Considering the profile of the potential adverse effects, particularly the likelihood of increasing the risk of heart failure, thiazolidinediones are currently not recommended in treatment following heart transplantation due to the lack of scientific evidence that would prove the safety of this kind of therapy in the aforementioned group of patients [42].

It was demonstrated that sitagliptin and vildagliptin are safe and effective in treating PTDM following kidney or heart transplantation and no drug interaction was observed with immunosuppressive preparations administered after transplantation [43]. The metabolism of saxagliptin is mediated by cytochrome CYP3A4/5, therefore its interactions with immunosuppressants are likely, which makes it a poor choice in the treatment of PTDM. Another advantage of DPP-4 inhibitors is the possibility of their safe use in the treatment of patients with renal failure - linagliptin can be prescribed even without reducing doses, whereas saxagliptin, vildagliptin and sitagliptin can also be administered in cases of severe renal failure if lowered doses are used [44]. A pleiotropic effect of DPP-4 inhibitors on the remodeling and cytoprotection of the cardiac muscle was observed in animal models [45], yet the SAVOR-TIMI [46] and EXAMINE trials [47] indicated no significant influence of saxagliptin and alogliptin respectively on cardiovascular outcomes. However, the SAVOR-TIMI study demonstrated a $27 \%$ increase in heart failure-related hospitalization in patients taking saxagliptin [46]. Post-hoc analyses in the EXAMINE [47] and TECOS [48] trials indicated no increased risk of heart failure following the administration of alogliptin and sitagliptin, suggesting that the negative influence of saxagliptin can be related to the drug itself and not the entire group. However, the FDA issued a warning regarding the use of sitagliptin in patients with increased risk of heart failure. Based on the preliminary trials of DPP-4 inhibitors and the recommendations of the FDA, sitagliptin and saxagliptin should not be administered to heart transplant patients. There is no clinical data that would make it possible to give an explicit recommendation as to which type of incretin-based therapy would be the most beneficial in the treatment of PTDM after heart transplantation. The more favorable profile of adverse effects and the ease of administering DPP-4 inhibitors compared to GLP-1 agonists suggests that the former will be better tolerated. However, the emerging reports regarding the advantages of using GLP-1 agonists in type-2 diabetes in the context of preventing cardiovascular events demonstrate the necessity of conducting large-scale studies comparing these two types of drugs in the treatment of PTDM [42].

Despite the need for large-scale trials, current reports suggest that it is appropriate to administer SGLT-2 inhibitors to heart transplant patients. The beneficial effects of these drugs in the diabetic population primarily involved the significant reduction in heart failure incidence and heart failure-related hospitalization [49]. Considering these observations, research is currently being conducted on groups of non-diabetic patients with heart failure, therefore SGLT- 2 inhibitors could potentially become the basis of PTDM treatment in the future.

Insulin therapy is the first-line treatment during the perioperative period in transplantation, but patients with prior diagnosed diabetes may continue the regimen followed before the transplantation. However, for patients with unbalanced plasma glucose levels, it is recommended to continue insulin therapy with frequent plasma glucose measurements, while striving to lower the insulin doses with prospective modifications aimed at oral treatment.

Post-transplant hyperglycemia, regardless of whether it has been classified as NODAT or PTDM, requires the introduction of intravenous insulin therapy and hourly monitoring of plasma glucose in the period directly after transplantation, particularly given the administration of high doses of immunosuppressants. Following the first week after transplantation, it should be replaced with subcutaneous insulin therapy, and 
Table 5. Effects of oral anti-diabetic medications in post-solid organ transplant patients

\begin{tabular}{|c|c|}
\hline $\begin{array}{l}\text { Medication administered during } \\
\text { the treatment of NODAT }\end{array}$ & Effects in post-transplant patients \\
\hline Metformin & $\begin{array}{l}\text { - Safe use } \\
\text { - Inadvisable during urgent hospitalization }\end{array}$ \\
\hline Sulfonylureas & $\begin{array}{l}\text { - Higher risk of hypoglycemia } \\
\text { - Necessity to modify doses relative to the level of kidney failure } \\
\text { - Special care required in the case of elderly patients } \\
\text { - No influence on the pharmacokinetics of ciclosporin }\end{array}$ \\
\hline Alpha-glucosidase inhibitor & - No studies thus far \\
\hline GLP-1 receptor agonists & - Liraglutide exhibited no effect on the concentration of tacrolimus \\
\hline DPP-4 inhibitors & $\begin{array}{l}\text { - No interactions with immunosuppressants } \\
\text { - Safe use }\end{array}$ \\
\hline PPAR agonist & $\begin{array}{l}\text { - Relatively effective and safe } \\
\text { - Increased insulin sensitivity } \\
\text { - Slow initial effect } \\
\text { - Slight risk of hypoglycemia } \\
\text { - Fluid retention }\end{array}$ \\
\hline SGLT-2 inhibitors & $\begin{array}{l}\text { - Result in dehydration and hypotension, and increased risk of genitourinary system infections } \\
\text { - Risk of ketoacidosis }\end{array}$ \\
\hline
\end{tabular}

the administration of oral anti-diabetic medication can be considered. The subcutaneous insulin dose should be calculated based on its intravenous form in the last 24 hours. The level of plasma glucose should be monitored 4 times per day. Afterwards, if there are no contraindications, oral anti-diabetic medication can be introduced.

Though the studies conducted thus far have not demonstrated a preferred treatment model involving oral anti-diabetic medication, typically the decision to commence therapy is based on the risk of the occurrence of interactions with immunosuppressants, and the occurrence of adverse effects (Table 5) [9, 15].

\section{Antihypertensive therapy}

The general target of arterial pressure control in diabetic patients is a value $<130 / 80 \mathrm{~mm} \mathrm{Hg}$ (in individuals aged $>65$ the value is $<140 / 80 \mathrm{~mm} \mathrm{Hg}$ ). The arterial hypertension therapy in this group of patients is commenced with thiazide diuretics and calcium channel blockers, which exhibit nephroprotective effects in patients with calcineurin inhibitors (ciclosporin, tacrolimus) administered in their treatment protocol. In the case of kidney transplant patients, while angiotensinconverting enzyme (ACE) inhibitors and angiotensin receptor antagonists AT1 are preferred in the treatment of hypertension in patients with type 2 diabetes, the occurrence of renal artery stenosis must be excluded before they are introduced [30].

\section{Lipid metabolism disorder treatment}

The primary goal of this type of treatment is to decrease the concentration of LDL cholesterol. Lifestyle modifications and plasma glucose control are recommended initially, but when the goal of treatment is not achieved, it is recommended to administer statins. Fluvastatin is recommended in the case of kidney transplant patients due to its nephroprotective effects. Furthermore, Prasad et al. [33] proved that the administration of these medications lowers the risk of developing new onset diabetes after transplantation and additionally decreases insulin resistance and provides anti-inflammatory effects. Particular attention should be called to the combination of calcineurin inhibitors with $\mathrm{HMG}-\mathrm{CoA}$ reductase inhibitors, as they may result in rhabdomyolysis.

It still remains to be settled whether hypertriglyceridemia is an independent risk factor for cardiovascular diseases. The therapy aimed at lowering lipid concentration, statin should remain the primary strategy, but fibrates should be administered to patients with very high triglycerides, who are at risk of pancreatitis. However, no additional benefits are achieved when adding fibrate to statin in the case of patients with diabetes, which was demonstrated in the ACCORD study assessing the cardiovascular risks in diabetes [50]. Furthermore, all fibrates, except gemfibrozil, are nephrotoxic, therefore care should be taken when administering these drugs to post-transplant patients, particularly in 
cases of renal failure. It was also demonstrated that fenofibrate decreases the concentration of ciclosporin in the recipient after heart transplantation. Therefore, administering fibrates requires great caution and the precise monitoring of the level of immunosuppressants, as well as controlling liver function and observing for any alarming symptoms [50].

A full lipid profile should be monitored in the case of all adult kidney recipients from the $2^{\text {nd }}$ to the $3^{\text {rd }}$ month following the operation, and after 2-3 months following a change in the immunosuppressive therapy or following the occurrence of other factors resulting in dyslipidemia. Depending on the results, KIDIGO prepared the following recommendations:

- in the case of kidney recipients with fasting TG concentration $\geq 500 \mathrm{mg} / \mathrm{dL}$, life style changes or drugs lowering triglyceride concentration should be introduced;

- treatment should be introduced at LDL cholesterol levels $\geq 100 \mathrm{mg} / \mathrm{dL}$ to lower its level below $100 \mathrm{mg} / \mathrm{dL}$;

- in the case of patients with normal LDL choleste$\mathrm{rol}, \mathrm{TG} \geq 200 \mathrm{mg} / \mathrm{dL}$ and non-HDL-ch $\geq 130 \mathrm{mg} / \mathrm{dL}$, treatment should be introduced in such a way so as to lower the level of non-HDL-ch below 130 $\mathrm{mg} / \mathrm{dL}$ [36].

\section{Complications}

As a result of the occurrence of one of the most common complications of solid organ transplantation, new onset diabetes after transplantation, there is an increased risk of infection and cardiovascular incidents, and risk of death associated with the failure of the transplanted organ [46].

\section{Summary}

More and more patients have been subjected to solid organ transplantation in recent years. This provides higher chances for the improvement of their quality of life, but such an operation carries the risk of the occurrence of adverse effects such as new onset diabetes after transplantation. NODAT is associated with increased risk of acute graft rejection through infections, circulatory system diseases and risk of death. Apart from traditional risk factors concerning type 2 diabetes, the patients are also exposed to immunosuppressive therapy. The early identification of high-risk patients during pre-transplantation screening, quick diagnosis and the early introduction of appropriate treatment as well as lifestyle modifications are all imperative in order to improve a patients' long-term prognosis. When selecting anti-diabetic therapy for a post-transplant patient, the toxicity and interactions be- tween medications have to be taken into consideration. Apart from hyperglycemia, the control of comorbidities such as dyslipidemia and arterial hypertension must be optimized as well. Future studies should develop immunosuppressive treatment regimens with minimal diabetogenic effects, determine the role of plasma glucose control in solid organ graft survival, and define interventions for primary prophylaxis against NODAT.

\section{Conflicts of interest}

The author declares no conflicts of interests.

\section{REFERENCES}

1. Rodrigo E, Fernández-Fresnedo G, Valero R, et al. New-onset diabetes after kidney transplantation: risk factors. J Am Soc Nephrol. 2006; 17(12 Suppl 3): S291-S295, doi: 10.1681/ ASN.2006080929, indexed in Pubmed: 17130277.

2. Milczarek M, Wojciechowska M, Mamcarz A, et al. Waskulopatia $w$ przeszczepionym sercu - nowe trendy $w$ diagnostyce $i$ leczeniu. Folia Cardiologica. 2017; 12(1): 50-54, doi: 10.5603/ fc.a2016.0066.

3. Chakkera HA, Weil EJ, Castro J, et al. Hyperglycemia during the immediate period after kidney transplantation. Clin J Am Soc Nephrol. 2009; 4(4): 853-859, doi: 10.2215/CJN.05471008, indexed in Pubmed: 19339426.

4. Bergrem HA, Valderhaug TG, Hartmann A, et al. Undiagnosed diabetes in kidney transplant candidates: a case-finding strategy. Clin J Am Soc Nephrol. 2010; 5(4): 616-622, doi: 10.2215/ CJN.07501009, indexed in Pubmed: 20133490.

5. Sharif A, Hecking M, de Vries APJ, et al. Proceedings from an international consensus meeting on posttransplantation diabetes mellitus: recommendations and future directions. Am J Transplant. 2014; 14(9): 1992-2000, doi: 10.1111/ajt.12850, indexed in Pubmed: 25307034.

6. Hecking M, Werzowa J, Haidinger M, et al. European-New-Onset Diabetes After Transplantation Working Group. Novel views on new-onset diabetes after transplantation: development, prevention and treatment. Nephrol Dial Transplant. 2013; 28(3): 550-566, doi: 10.1093/ndt/gfs583, indexed in Pubmed: 23328712.

7. Bloom RD, Crutchlow MF. New-onset diabetes mellitus in the kidney recipient: diagnosis and management strategies. Clin J Am Soc Nephrol. 2008; 3 Suppl 2: S38-S48, doi: 10.2215/CJN.02650707, indexed in Pubmed: 18309002.

8. Alberti KG, Zimmet PZ. Definition, diagnosis and classification of diabetes mellitus and its complications. Part 1: diagnosis and classification of diabetes mellitus provisional report of a WHO consultation. Diabet Med. 1998; 15(7): 539-553, doi: 10.1002/ (SICI)1096-9136(199807)15:7<539::AID-DIA668>3.0.CO;2-S, indexed in Pubmed: 9686693.

9. Araszkiewicz A, Bandurska-Stankiewicz E, Budzyński A, et al. 2019 Guidelines on the management of diabetic patients. A position of Diabetes Poland. Clinical Diabetology. 2019; 8(1): 1-95, doi: 10.5603/dk.2019.0001.

10. Armstrong KA, Prins JB, Beller EM, et al. Should an oral glucose tolerance test be performed routinely in all renal transplant recipients? Clin J Am Soc Nephrol. 2006; 1(1): 100-108, doi: 10.2215/ CJN.00090605, indexed in Pubmed: 17699196.

11. Ye X, Kuo HT, Sampaio MS, et al. Risk factors for development of new-onset diabetes mellitus after transplant in adult lung transplant recipients. Clin Transplant. 2011; 25(6): 885-891, doi: 10.1111/j.1399-0012.2010.01383.x, indexed in Pubmed: 21175848.

12. Montori VM, Basu A, Erwin PJ, et al. Posttransplantation diabetes: a systematic review of the literature. Diabetes Care. 2002; 25(3): 
583-592, doi: 10.2337/diacare.25.3.583, indexed in Pubmed: 11874952.

13. Hjelmesaeth J, Midtvedt $K$, Jenssen $T$, et al. Insulin resistance after renal transplantation: impact of immunosuppressive and antihypertensive therapy. Diabetes Care. 2001 ; 24(12): 2121-2126, doi: 10.2337/diacare.24.12.2121, indexed in Pubmed: 11723094.

14. Hjelmesaeth J, Asberg A, Müller F, et al. New-onset posttransplantation diabetes mellitus: insulin resistance or insulinopenia? Impact of immunosuppressive drugs, cytomegalovirus and hepatitis C virus infection. Curr Diabetes Rev. 2005; 1(1): 1-10, doi: 10.2174/1573399052952604, indexed in Pubmed: 18220577.

15. Pham PTT, Pham PMT, Pham SV, et al. New onset diabetes after transplantation (NODAT): an overview. Diabetes Metab Syndr Obes. 2011; 4: 175-186, doi: 10.2147/DMSO.S19027, indexed in Pubmed: 21760734.

16. Cosio FG, Pesavento TE, Osei K, Henry ML, Ferguson RM. Posttransplant diabetes mellitus: Increasing incidence in renal allograft recipients transplanted in recent years. Kidney Int. 2001; 59: 732-737. doi: 10.1046/j.1523-1755.2001.059002732.x.

17. Ye X, Kuo HT, Sampaio MS, et al. Risk factors for development of new-onset diabetes mellitus in adult heart transplant recipients. Transplantation. 2010; 89(12): 1526-1532, doi: 10.1097/ TP.0b013e3181dd6bd9, indexed in Pubmed: 20431437.

18. Kasiske BL, Snyder JJ, Gilbertson D, et al. Diabetes mellitus after kidney transplantation in the United States. Am J Transplant. 2003; 3(2): 178-185, doi: 10.1034/j.1600-6143.2003.00010.x, indexed in Pubmed: 12603213.

19. Dedinská I, Graňák K, Vnučák $M$, et al. Role of sex in posttransplant diabetes mellitus development: Are men and women equal? J Diabetes Complications. 2019; 33(4): 315-322, doi: 10.1016/j.jdiacomp.2018.12.017, indexed in Pubmed: 30755355.

20. Sumrani NB, Delaney V, Ding ZK, et al. Diabetes mellitus after renal transplantation in the cyclosporine era--an analysis of risk factors. Transplantation. 1991; 51(2): 343-347, doi: 10.1097/00007890199102000-00014, indexed in Pubmed: 1994525.

21. Martínez-Castelao A, Hernández MD, Pascual J, et al. investigators of the HIGLU study. Detection and treatment of post kidney transplant hyperglycemia: a Spanish multicenter cross-sectional study. Transplant Proc. 2005; 37(9): 3813-3816, doi: 10.1016/j. transproceed.2005.10.035, indexed in Pubmed: 16386547.

22. Baid S, Cosimi AB, Farrell ML, et al. Posttransplant diabetes mellitus in liver transplant recipients: risk factors, temporal relationship with hepatitis $C$ virus allograft hepatitis, and impact on mortality. Transplantation. 2001; 72(6): 1066-1072, doi: 10.1097/00007890-200109270-00015, indexed in Pubmed: 11579302.

23. Hjelmesaeth J, Sagedal S, Hartmann A, et al. Asymptomatic cytomegalovirus infection is associated with increased risk of new-onset diabetes mellitus and impaired insulin release after renal transplantation. Diabetologia. 2004; 47(9): 1550-1556, doi: 10.1007/s00125-004-1499-z, indexed in Pubmed: 15338129.

24. Hjelmesaeth J, Müller $F$, Jenssen $T$, et al. Is there a link between cytomegalovirus infection and new-onset posttransplantation diabetes mellitus? Potential mechanisms of virus induced beta-cell damage. Nephrol Dial Transplant. 2005; 20(11): 2311-2315, doi: 10.1093/ndt/gfi033, indexed in Pubmed: 16046502.

25. Schweer T, Gwinner W, Scheffner I, et al. High impact of rejection therapy on the incidence of post-transplant diabetes mellitus after kidney transplantation. Clin Transplant. 2014; 28(4): 512-519, doi: 10.1111/ctr.12329, indexed in Pubmed: 24649873.

26. Numakura K, Satoh S, Tsuchiya N, et al. Clinical and genetic risk factors for posttransplant diabetes mellitus in adult renal transplant recipients treated with tacrolimus. Transplantation. 2005; 80(10): 1419-1424, doi: 10.1097/01.tp.0000181142.82649.e3, indexed in Pubmed: 16340785.

27. Gourishankar S, Jhangri GS, Tonelli M, et al. Development of diabetes mellitus following kidney transplantation: a Canadian experience. Am J Transplant. 2004; 4(11): 1876-1882, doi: 10.1111/j.1600-6143.2004.00591.x, indexed in Pubmed: 15476489.

28. Yates CJ, Barraclough KA, McWhinney BC, et al. A practical limited sampling strategy to predict free prednisolone exposure and glycemia in kidney transplant recipients. Ther Drug Monit. 2014; 36(1): 18-23, doi: 10.1097/FTD.0b013e31829daae4, indexed in Pubmed: 24335760.

29. Cieniawski D, Miarka P, Jaśkowski $P$, et al. Cukrzyca potransplantacyjna - trudności w diagnostyce i rozpoznaniu. Varia Medica. 2018; 61873: 446-449.

30. Alebiosu OC, Ayodele OE. Natural history and epidemiology of post transplantation diabetes mellitus. Afr Health Sci. 2005; 5(3): 255-260, doi: 10.5555/afhs.2005.5.3.255, indexed in Pubmed: 16245997

31. Vincenti F, Friman S, Scheuermann E, et al. DIRECT (Diabetes Incidence after Renal Transplantation: Neoral C Monitoring Versus Tacrolimus) Investigators. Results of an international, randomized trial comparing glucose metabolism disorders and outcome with cyclosporine versus tacrolimus. Am J Transplant. 2007; 7(6): 1506-1514, doi: 10.1111/j.1600-6143.2007.01749.x, indexed in Pubmed: 17359512.

32. Heisel O, Heisel R, Balshaw R, Keown P. New onset diabetes mellitus in patients receiving calcineurin inhibitors: a systematic review and meta-analysis. Am J Transplant. 2004; 4(4): 583-595, doi: 10.1046/j.1600-6143.2003.00372.x.

33. Prasad GV, Kim SJ, Huang M, et al. Reduced incidence of newonset diabetes mellitus after renal transplantation with 3-hydroxy3-methylglutaryl-coenzyme a reductase inhibitors (statins). Am J Transplant. 2004; 4(11): 1897-1903, doi: 10.1046/j.16006143.2004.00598.x, indexed in Pubmed: 15476492.

34. Flechner SM, Glyda M, Cockfield S, et al. The ORION study: comparison of two sirolimus-based regimens versus tacrolimus and mycophenolate mofetil in renal allograft recipients. Am J Transplant. 2011; 11(8): 1633-1644, doi: 10.1111/j.16006143.2011.03573.x, indexed in Pubmed: 21668635.

35. Johnston $\mathrm{O}$, Rose $\mathrm{CL}$, Webster $\mathrm{AC}$, et al. Sirolimus is associated with new-onset diabetes in kidney transplant recipients. J Am Soc Nephrol. 2008; 19(7): 1411-1418, doi: 10.1681/ ASN.2007111202, indexed in Pubmed: 18385422

36. Durlik M, Polskie Towarzystwo Transplantacyjne, Zalecenia dotyczące leczenia immunosupresyjnego po przeszczepieniu narządów unaczynionych, 2014.

37. Vest LS, Koraishy FM, Zhang Z, et al. Metformin use in the first year after kidney transplant, correlates, and associated outcomes in diabetic transplant recipients: A retrospective analysis of integrated registry and pharmacy claims data. Clin Transplant. 2018; 32(8): e13302, doi: 10.1111/ctr.13302, indexed in Pubmed: 29851159.

38. Palepu S, Prasad GV. New-onset diabetes mellitus after kidney transplantation: Current status and future directions. World J Diabetes. 2015; 6(3): 445-455, doi: 10.4239/wjd.v6.i3.445, indexed in Pubmed: 25897355.

39. Balas B, Belfort R, Harrison SA, et al. Pioglitazone treatment increases whole body fat but not total body water in patients with non-alcoholic steatohepatitis. J Hepatol. 2007; 47(4): 565-570, doi: 10.1016/j.jhep.2007.04.013, indexed in Pubmed: 17560678.

40. Habib ZA, Havstad SL, Wells K, et al. Thiazolidinedione use and the longitudinal risk of fractures in patients with type 2 diabetes mellitus. J Clin Endocrinol Metab. 2010; 95(2): 592-600, doi: 10.1210/jc.2009-1385, indexed in Pubmed: 20061432.

41. Kermode-Scott B. Meta-analysis confirms raised risk of bladder cancer from pioglitazone. BMJ. 2012; 345: e4541, doi: 10.1136/ bmj.e4541, indexed in Pubmed: 22763399.

42. Cehic MG, Nundall N, Greenfield JR, et al. Management Strategies for Posttransplant Diabetes Mellitus after Heart Transplantation: A Review. J Transplant. 2018; 2018: 1025893, doi: 10.1155/2018/1025893, indexed in Pubmed: 29623219.

43. Boerner BP, Miles CD, Shivaswamy V. Efficacy and safety of sitagliptin for the treatment of new-onset diabetes after renal 
transplantation. Int J Endocrinol. 2014; 2014: 617638, doi: 10.1155/2014/617638, indexed in Pubmed: 24817885.

44. Arjona Ferreira JC, Corry D, Mogensen CE, et al. Efficacy and safety of sitagliptin in patients with type 2 diabetes and ESRD receiving dialysis: a 54-week randomized trial. Am J Kidney Dis. 2013; 61(4): 579-587, doi: 10.1053/j.ajkd.2012.11.043, indexed in Pubmed: 23352379.

45. Ravassa S, Zudaire A, Díez J. GLP-1 and cardioprotection: from bench to bedside. Cardiovasc Res. 2012; 94(2): 316-323, doi: 10.1093/cvr/cvs123, indexed in Pubmed: 22419668.

46. Scirica BM, Bhatt DL, Braunwald E, et al. SAVOR-TIMI 53 Steering Committee and Investigators. Saxagliptin and cardiovascular outcomes in patients with type 2 diabetes mellitus. $\mathrm{N}$ Engl J Med. 2013; 369(14): 1317-1326, doi: 10.1056/NEJMoa1307684, indexed in Pubmed: 23992601.
47. White WB, Cannon CP, Heller SR, et al. EXAMINE Investigators. Alogliptin after acute coronary syndrome in patients with type 2 diabetes. N Engl J Med. 2013; 369(14): 1327-1335, doi: 10.1056/ NEJMoa1305889, indexed in Pubmed: 23992602.

48. Green JB, Bethel MA, Armstrong PW, et al. TECOS Study Group. Effect of Sitagliptin on Cardiovascular Outcomes in Type 2 Diabetes. N Engl J Med. 2015; 373(3): 232-242, doi: 10.1056/ NEJMoa1501352, indexed in Pubmed: 26052984.

49. Zinman B, Wanner C, Lachin JM, et al. EMPA-REG OUTCOME Investigators. Empagliflozin, Cardiovascular Outcomes, and Mortality in Type 2 Diabetes. N Engl J Med. 2015; 373(22): 2117-2128, doi: 10.1056/NEJMoa1504720, indexed in Pubmed: 26378978.

50. Elam M, Lovato L, Ginsberg H. The ACCORD-Lipid study: implications for treatment of dyslipidemia in Type 2 diabetes mellitus. Clin Lipidol. 2011; 6(1): 9-20, doi: 10.2217/clp.10.84, indexed in Pubmed: 26207146. 